\title{
"Perceptions of the financial sustainability of an indigent policy in a selected municipality in the western cape, South Africa"
}

\begin{tabular}{|c|c|}
\hline AUTHORS & $\begin{array}{l}\text { Robert Schultz (D http://orcid.org/0000-0002-8139-5782 } \\
\text { Rozenda Hendrickse }\end{array}$ \\
\hline ARTICLE INFO & $\begin{array}{l}\text { Robert Schultz and Rozenda Hendrickse (2018). Perceptions of the financial } \\
\text { sustainability of an indigent policy in a selected municipality in the western cape, } \\
\text { South Africa. Problems and Perspectives in Management, 16(2), 12-22. } \\
\text { doi:10.21511/ppm.16(2).2018.02 }\end{array}$ \\
\hline DOI & http://dx.doi.org/10.21511/ppm.16(2).2018.02 \\
\hline RELEASED ON & Tuesday, 17 April 2018 \\
\hline RECEIVED ON & Monday, 11 September 2017 \\
\hline ACCEPTED ON & Thursday, 25 January 2018 \\
\hline LICENSE & $\begin{array}{l}(c) \text { EY-NG } \\
\text { This work is licensed under a Creative Commons Attribution-NonCommercial } 4.0 \\
\text { International License }\end{array}$ \\
\hline JOURNAL & "Problems and Perspectives in Management" \\
\hline ISSN PRINT & $1727-7051$ \\
\hline ISSN ONLINE & $1810-5467$ \\
\hline PUBLISHER & LLC "Consulting Publishing Company "Business Perspectives" \\
\hline FOUNDER & LLC "Consulting Publishing Company "Business Perspectives" \\
\hline
\end{tabular}

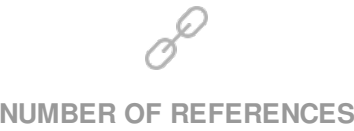

27
NUMBER OF FIGURES

0
NUMBER OF TABLES

0

(C) The author(s) 2023. This publication is an open access article. 


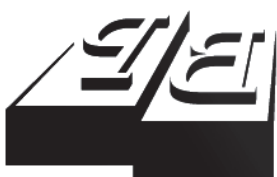

BUSINESS PERSPECTIVES

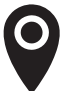

LLC "CPC "Business Perspectives" Hryhorii Skovoroda lane, 10, Sumy, 40022, Ukraine

www.businessperspectives.org

Received on: $11^{\text {th }}$ of September, 2017 Accepted on: $25^{\text {th }}$ of January, 2018

(C) Robert Schultz, Rozenda Hendrickse, 2018

Robert Schultz, Faculty of Business \& Management Sciences, Department of Public Administration and Governance, South Africa.

Rozenda Hendrickse, Professor, Faculty of Business \& Management Sciences, Department of Public Administration and Governance, South Africa.

\section{(ㄷ)(1) $(8)$}

This is an Open Access article, distributed under the terms of the Creative Commons Attribution-NonCommercial 4.0 International license, which permits re-use, distribution, and reproduction, provided the materials aren't used for commercial purposes and the original work is properly cited.
Robert Schultz (South Africa), Rozenda Hendrickse (South Africa)

PERCEPTIONS OF THE FINANCIAL SUSTAINABILITY OF AN INDIGENT POLICY IN A SELECTED MUNICIPALITY IN THE WESTERN CAPE, SOUTH AFRICA

\begin{abstract}
The eradication of poverty is an important priority for the South African government. The Constitution makes provision for vulnerable households and, therefore, local government has to develop policies to address the needs of the poor. Municipalities developed and adopted Indigent Policies to ensure that the poor households have access to essential basic services. This led the researcher to in vestigate what challenges are related to the financial sustainability of the Indigent Policy in its implementation process at the City of Cape Town for the period from 2003 to 2016. This study followed a qualitative research approach. Data were collected by conducting in-depth interviews. The participants were selected, because they had access to the most recent information that relates to the Indigent Policy. The researcher respected the rights of participants by allowing them the freedom to withdraw at any stage of the research study, ensuring confidentiality, ensuring anonymity, ensuring fair treatment and protecting the participants from any harm and discomfort throughout the research study. The researcher is of the opinion that all of the respondents are confident that the Indigent Policy is sustainable. However, should it become too expensive for the City of Cape Town to maintain the Indigent Policy, it could result in the budget of some other services being reprioritized. It is recommended that the City of Cape Town develops a beneficiary system for qualified indigents to allow them to receive additional benefits from other City of Cape Town facilities such as libraries, swimming pools and the MyCiTi bus services.
\end{abstract}

\section{Keywords}

JEL Classification financial sustainability, municipality, Indigent Policy, poverty, basic services

\section{INTRODUCTION}

The eradication of poverty is one of the most important priorities for the government of South Africa (Bhorat, Oosthuizen, \& van der Westhuizen, 2012, p. 77). According to Thorton (2015, p. 91), the government is a major stakeholder in the economy of a country. The national, provincial and local governments make up a large share of the economy. The different spheres of government have a role in the economy through the taxes they levy on its citizens, the goods and services Government buys and the people they employ. Areyeetey, Devarajan, Kanbur, and Kasekende (2012, p. 234) state that Sub-Saharan Africa is the only region in the developing world where the proportion of the poor has not declined during the period from 1981 and 2005 - the number of poor has actually increased significantly.

"Due to the level of unemployment and poverty within municipal areas, there are both households and citizens who are unable to access or pay for basic services; this grouping is referred to as the indigent. A 
municipality, therefore, needs to develop and adopt an Indigent Policy to ensure that the indigent can have access to the package of services included in the free basic services program" (The Department of Provincial and Local Government, 2006, p. 12).

In terms of Section 27 of the South African Constitution (Act 108 of 1996) (1), hereafter referred to as the Constitution, "everyone has the right to have access to health care services, including reproductive health care; sufficient food and water; social security, including, if they are unable to support themselves and their dependants and appropriate social assistance". This right to access basic services is protected in Chapter 2 of the Constitution; Section 27(b) of the Bill of Rights. Chapter 7 of the Constitution Section 155 (4) entrusts the local governments and local municipalities with the provision of municipal services in an equitable and sustainable manner as stipulated in the Municipal Finance Management Acts. Municipalities in South Africa play an important role in providing access to basic services to communities who are unable to pay consistently for the essential services and municipal rates.

The Constitution gives municipalities autonomous powers. Municipalities within the City of Cape Town metropolitan area have rights to govern the communities they serve. The council of the City of Cape Town is elected by the electorate and public officials are responsible for the coordination and implementation of municipal functions approved by the relevant council. In light of the foregoing, the objective of this study was to determine whether or not the Indigent Policy as adopted by the City of Cape Town is financially sustainable.

\section{BACKGROUND TO RESEARCH PROBLEM}

On April 27, 1994 South Africa became a democratic state, underpinned by a new Constitution. According to the 1994 Constitution, each individual has a legal right to have access to basic services. Black, Calitz, and Steenekamp (2008, p. 5) state that the constitutional change in South Africa occurred at a time when the roles and functions of different governments were reviewed across the world. Initially growing consensus emerged that developing countries and economies require small deficits, as well as lower levels of public debt. There was also a general agreement that fiscal constraints required a thorough revision of the basic functions the Government is responsible for.

In South Africa, resources are scarce, unemployment is increasing and the supply and demand mechanisms are not sufficient. Government are supposed to intervene to provide services to those individuals who otherwise cannot afford them. Government, therefore, assumes final responsibility for the country's economic well-being, on the one hand, and the general welfare of society, the poor in particular, on the other hand. The provisions stipulated in each indigent grant should be the best mix of the two focus areas of government - a test that should be conducted on a needs basis, as circumstances within the world economy unfold (Visser \& Erasmus, 2002, p. 2).

The City of Cape Town's Indigent Policy (2003, p. 5) was developed as a result of the urgent need to address the high levels of chronic poverty in the city and the constitutional right for free basic service delivery to the poor.

\section{STATEMENT OF THE RESEARCH PROBLEM}

In line with Brink, van der Walt and van Rensburg's (2012, p. 61) definition of a research problem, it is possible that a research problem is formulated from sources other than a problematic situation, such as the researcher's specific interest in a certain topic. The Constitution makes provision for vulnerable households and, therefore, local government has to develop policies to address the needs of the poor. Municipalities developed and adopted Indigent Policies to ensure that the poor households have access to essential basic services. This led the researcher to investigate what challenges are related to the financial sustainability of the Indigent Policy in its implementation process at the City of Cape Town for the period from 2003 to 2016 . 


\section{RESEARCH OBJECTIVE}

The core objective of the study was to investigate what challenges are related to the financial sustainability of the Indigent Policy in its implementation process at the City of Cape Town for the period from 2003 to 2016.

\section{LITERATURE REVIEW}

The research study investigated different approaches, proposals and recommendations made by previous researchers in other governmental departments within South Africa. This was done prior to the researcher conducting his study at the City of Cape Town. The rationale was to eliminate any shortcomings experienced by previous researchers. The study was located within the realm of a public policy evaluation perspective.

Du Toit, Knipe, van Niekerk, van der Walt, and Dovle (2002, p. 123) explain that finance is the heartbeat of every nation and that without finance, it would be impossible for any government to survive, let alone provide the services that the public require. Every government department or institution should have funds to provide the necessary services and contribute to the development of the country. Most government institutions do not have the capacity to generate their own funds. They are, therefore, dependent on the central government and the National Revenue Fund. These funds need to be allocated to each department according to its individual needs, as well as the community it serves.

Visser and Erasmus (2002, pp. 2-3) explain that the basic needs of people - food, housing, medical care, water and electricity, and protection - are satisfied by various means. These primary needs constitute the lowest levels in the needs hierarchy. In a utopian society, unemployment would not exist, sufficient resources would be available to all, and each person would have the means to purchase all that they require to satisfy their needs. The supply and demand mechanism - in a free market economy - would also evenly distribute and allocate the services and functions required by individuals. Unfortunately, ours is not a perfect world. Resources are limited, unemployment is a global concern and the supply and demand mechanism is not sufficient to distribute and allocate scarce resources on a fair and equitable basis. The inability of the supply and demand mechanism to deliver services creates a vacuum which is filled by government. If the government intervenes to provide services and functions to those who cannot otherwise obtain them, it follows that such provisions would be morally rather than economically based.

Various piece of legislations govern the Indigent Policy; inter alia: The Constitution, The Public Financial Management Act 1 of 1999, The Division of Revenue Bill, Municipal Finance Management Act 53 of 2003, Municipal Finance Management Act circular No. 58, The National Development Plan 2030, National Framework for Municipal Indigent Policies and The Municipal Indigent Policy. When dealing with the Indigent Policy, the content of the Acts may not be ignored.

\section{RESEARCH METHODOLOGY}

This study followed a qualitative research approach, as the researcher aimed at getting views, perceptions and interpretations of the participants involved around the financial sustainability of the Indigent Policy and the provision of free basic services. The researcher decided on this method, as the researcher felt that this approach provided the opportunity to interact with individuals who would identify others who would offer the opportunity to share their first-hand experiences and interpretations of legislation, policies and data that affect the delivery of free basic services as stipulated in the Indigent Policy of the City of Cape Town to the communities within their jurisdiction. The data obtained were interpreted, analyzed, concluded and were forwarded together with recommendations to the office of the City Manager at the City of Cape Town for possible interventions.

\section{DATA COLLECTION}

The study collected its data by means of in-depth interviews. According to Hennink, Hutter, and Bailey (2011, p. 109), an in-depth interview is a one-to-one method of data collection that in- 
volves an interviewer and an interviewee to discuss specific topics in-depth. Hennink et al. (2011, p. 109) further define an in-depth interview as a conversation with a purpose. The researcher's purpose is to gain insight into certain issues using a semi-structured interview guide.

The researcher decided to use in-depth interviews as a method of acquiring information, as Kumar (2007, p. 109) explained that in-depth interview refers to an interview held in a form of a group or a one-to-one interview. This approach to data collection is extremely useful in situations where either in depth information is needed or little is known about the area.

Leedy and Ormrod (2014, p. 153) explain that it is quite common in qualitative studies to identify sources that are considered appropriate sources, because the data required for the study by the researcher will be shared by the identified sources. Fink $(2014$, p. 100) agrees that research studies depend on accurate data and that data should be obtained from credible sources who will share relevant data. This sentiment is also shared by Salmons $(2015$, p. 116$)$ who argues that it is criti$\mathrm{cal}$ in research studies to select individuals who are in a position to contribute their knowledge and experiences to the research study. The researcher has developed consent forms that explained the rights of the participants. The consent forms were presented and discussed with each participant to obtain their commitment to partake in the study.

The researcher specifically chose the participants as they were considered to be appropriate sources, because they have access to the data which are required in this study. The participants gave their prior willingness to share relevant data, knowledge and experiences. The researcher purposely selected the following officials: Director: Budgets, Director: Revenue, Finance Manager: Water Services, Finance Manager: Electricity Services, Finance Manager: Solid Waste.

The researcher has decided to use the purposive sampling method while allowing room to use the snowball sampling method. Morse and Richards (2002, p. 173) warned researchers that they should be cognisant when using the purposive sampling method, as this sampling method may often not be representative of the entire population. The researcher has allowed room for snowball sampling, because the initial sample may identify other relevant stakeholders who may add value to the study. The researcher made use of this sampling method as this approach will provide the opportunity to interact with individuals who may identify others who have the opportunity to share their real life experiences and interpretations of legislation, policies and data that affect the delivery of free basic services as stipulated in the Indigent Policy of the City of Cape Town.

The limitations that the researcher were faced with were, firstly, identifying the correct participants for the sample, secondly, setting up the interview sessions due to the demographics of the City of Cape Town, thirdly, the workload of the participants that made it difficult to avail themselves for interviews, fourthly, the environment of each of the stakeholders that influenced their daily lives and, fifthly, the bureaucracy of the university and organization which delayed activities of the research study.

\section{DATA ANALYSIS}

Data analysis is defined by Business Dictionary (2017) as the process that the researcher follows when evaluating collected data in a logical and diagnostic manner. It is possible that data are collected from a range of sources. The data should be studied by the researcher so that the researcher is in a position to make informed conclusions. Study. com (2017) agrees that data analysis comprises of a method followed by researchers whereby data are collected and sorted in such a way that researchers can obtain valuable information. Data may be collected using various different data collection methods. The data collection method used will be determined by the type of research that is being conducted. Observations, interviews and surveys are typical data collection methods.

Narration of the findings

Question 1: What procedures are in place for the implementation of the Indigent Policy at the City of Cape Town? 


\section{Response}

The City of Cape Town has a Constitutional Mandate to provide essential basic services to citizens deemed as indigent. The researcher has established that the City of Cape Town is implementing its Constitutional Mandate regarding indigents. This statement can be solidified by the fact that the City of Cape Town has developed and implemented the Indigent Policy to give effect to its Constitutional Mandate.

\section{Interpretation}

The researcher's logic for posing this particular question was to determine the level of awareness that the research participants had regarding the research topic. The researcher envisaged that due to the structure of the City of Cape Town and the various services provided to those deemed as indigent, each participant would highlight unique procedures used to implement the Indigent Policy.

All of the respondents agreed that public participation is important during the budgetary processes. The respondents further agreed that communication is a fundamental requirement for the successful implementation of the Indigent Policy at the City of Cape Town. Other common procedures included the development of information systems that was unique to the services being provided to the indigent and the application process linked to it.

The Constitution of the Republic of South Africa Act 108 of 1996 maintains that the state must make use of its resources to provide its citizens with access to services and appropriate social assistance (Constitution, 1996, p. 12). The researcher has ascertained that the City of Cape Town has indeed endeavoured to fulfil its obligation to assist the citizens that are deemed indigent. This indeed proves that what the research participants have alluded to is confirmed by literature.

\section{Question 2: What methods are used by the City of Cape Town to identify indigents?}

\section{Response}

Upon interviewing the participants of the study, the researcher has determined that specific criteria exist to identify indigents. The City of Cape
Town makes use of two methods that can be described as the targeted method which is based on joint household income not exceeding R3,500 per month and the valuation of the property method in which a properties valuation does not exceed R300,000. The criteria used to identify indigents for these two methods do allow for exception to the rule, for example, where households who have a joint income of more than $\mathrm{R} 3,500$, but own a property that's valuation is less than R300,000 will still receive some benefits.

An application process is applicable for all those households with a joint household income of less than R3,500 per month. Data sets for rates rebates are automatically implemented for properties valued at less than R300,000. All of the participants were in agreement that two methods exist to identify indigent at the City of Cape Town.

\section{Interpretation}

The researcher was curious to determine what methods the City of Cape Town uses to identify indigents. This curiosity led the researcher to posing the aforementioned question. It was determined that only two methods exist to identify indigent beneficiaries within the City of Cape Town. The two methods described above are the targeted method and the valuation of property method. This allows the City of Cape Town to effectively monitor and evaluate the amount of indigent beneficiaries. This information is important for the budgeting processes and also used for trend analysis and budget forecasting. The major difference between the two methods is that the initial method requires those considered as indigent to physically apply for the benefits, while the latter automatically calculates and awards the qualifying citizens the benefits.

City of Cape Town (2017) indicated that a person applying for indigent relief based on joint household income, should do so by following the approved processes. The processes followed by the City of Cape Town staff are in line with current literature.

\section{Question 3: Has the City of Cape Town engaged in any Indigent Policy awareness campaigns? Explain how (if yes) and why not (if no).}




\section{Response}

The respondent's feedback indicated that each of the line functions all have unique mandates regarding creating awareness of the Indigent Policy. The City of Cape Town engages in awareness programs to promote the Indigent Policy through public participation during the budgetary processes; presentations by staff of the City of Cape Town at sub-council and ward committee meetings; media releases through the political offices including newspaper and radio; pamphlets which are distributed with the municipal monthly accounts; notices at libraries and circulars.

\section{Interpretation}

Respondents are all in agreement that the City of Cape Town engages in Indigent Policy awareness programs listed above. These programs may differ from one line function to the next based on their individual mandates. The researcher has ascertained via the interviews conducted that the awareness programs listed above are implemented for the sole purpose of raising awareness regarding the Indigent Policy. This enables the City of Cape Town to reach as many eligible citizens as possible. There are, however, very specific types of programs linked to each line function based on its' mandate. For example the Directorate: Revenue will solely be responsible for ensuring that information pamphlets are included with the monthly municipal account sent to the users of municipal services.

The importance of creating awareness regarding policies should not be underestimated. In situations where resources are scarce and poverty prevails, awareness should be prioritized (Science Direct, 2013).

The researcher is of the opinion that the City of Cape Town understands the importance of awareness programs and actively engages in efforts to create the required awareness.

\section{Question 4: How does the City of Cape Town monitor the indigent register?}

\section{Response}

All respondents agreed that the monitoring of the indigent register at the City of Cape Town is monitored on a monthly basis by corporate revenue. The researcher was informed that the register is not only monitored, but also updated on a monthly basis. It was further established that the approval granted by the City of Cape Town is valid for a period not exceeding twelve months. The researcher established that the indigent register only consists of citizens that has applied and has been deemed indigent based on the fact that they combined household income did not exceed R3,500 per month. The quantity of beneficiaries that does not appear on the register outweighs the quantity of beneficiaries that qualified were through the application process. Beneficiaries are required to re-apply on an annual basis and will automatically be disqualified should they fail to re-apply. Beneficiaries are notified three months prior to the end of the twelve-month cycle, which allows the beneficiary to prepare relevant documents required for the application. This process allows the City of Cape Town to continuously monitor and evaluate the amount of applications.

\section{Interpretation}

Based on the feedback received from the research participants, it can be deduced that the register does not include the citizens (beneficiaries) who automatically qualify due to the valuation of their property. It is evident that those citizens deemed as indigent through the application process will be entitled to the indigent benefits for a maximum period of twelve months and would thereafter need to re-apply for the following year. The twelvemonth cycle is not restricted to a specific starting date, for example, applicants are not restricted to apply only in January. This for that reason requires the City of Cape Town to monitor the register on a monthly basis. The researcher is of the opinion that the reason for the annual application may be due to the fact that circumstances in an indigent's household may change favorably, resulting in the combined household income exceeding the maximum amount of R3,500 per month, which would inevitably influence the eligibility of the household.

It is imperative for any organization to implement registers when dealing with applicants. These registers can then be used as a tool to improve service delivery. Once registers are implemented, it is im- 
portant to constantly update it, as managers will use these registers as a basis for the effective and efficient monitoring and evaluation of the program (South Africa. The Presidency Department of Performance Monitoring and Evaluation, 2013, p. 11).

The researcher has established that the City of Cape Town implemented and updates the indigent register on a monthly basis. It has further been established that the citizens who appear on the indigent register are reminded to re-apply well in advance in order to ensure that they continue to receive the indigent benefits.

\section{Question 5: What are the legal implications of the application process?}

\section{Response}

All participants agreed that there are legal implications for falsifying information during the application process.

It was determined by the researcher that it is incumbent for applicants who do not automatically qualify to complete an application form to be considered as indigent. This application form must be signed by the applicant and have all supporting documents attached and, therefore, becomes a legal and binding document. The City of Cape Town expects that the citizens applying for indigent status are responsible citizens who are truthful in their applications. However, should the City of Cape Town establish that an applicant has falsified information on the application form, then all benefits will automatically be stopped. The applicant will be excluded from indigent status. Should the applicant be removed from the indigent register, the status of the applicant would change to someone who is eligible to pay for services received. All benefits are calculated in monetary value and reclaimed from the applicant. In the extreme cases, on merit, the City of Cape Town has the right to peruse criminal charges.

\section{Interpretation}

The application process for those who wish to be deemed as indigent is a fairly structured and organized process. It requires applicants to produce relevant documentation and in the absence of these documents, the policy allows applicants to obtain affidavits confirming their information. There are, however, implications for falsifying information produced on application forms. These implications range from the minimum penalty of the applicant's indigent status being revoked to a more severe penalty such as criminal charges being laid against the applicant.

The South African Labor Guide (2017) is of the opinion that the following are examples of types of dishonesty that falsification of information on applications is a type of dishonesty.

The researcher has established that the City of Cape Town has implemented fair processes to deal with cases in which applications were falsified. Through these processes the City of Cape Town ensures that only those citizens who are eligible receives the benefits of the Indigent Policy.

\section{Question 6: How does the City of Cape Town ensure that the application and verification processes are transparent?}

\section{Response}

All participants agreed that the application and verification process should be transparent. The City of Cape Town strives to ensure that the application and verification processes are transparent through public participation and enforcing Batho Pele principles.

The Batho Pele principles were introduced to improve the quality of service delivery by the government to its citizens (South Africa. The Department of Community Safety and Liaison, 2011, p. 1).

\section{Interpretation}

Although participants were knowledgeable about the process, three of the respondents directed the researcher to the Director: Revenue, as it is their core function. It was determined by the researcher that the application and verification process should be transparent. When dealing with citizens, government officials should always maintain the highest form of courtesy and portray good service standards, customer care and leadership skills. The officials at the City of Cape Town, as is 
the case with all government departments, are encouraged to uphold the Batho Pele principles and are guided by the notion of putting the needs of the citizens first.

Black, Calitz, and Steenekamp (2015, p. 369) explain that transparency means to be open to the public regarding the functions of government. It is perceived that openness and transparency may enhance the credibility of policies.

\section{Question 7: Which measures are implemented to ensure the successful operation of the Indigent Policy at the City of Cape Town?}

\section{Response}

The respondents were all able to provide feedback regarding the specific measures which are implemented in order to ensure the successful operation of the Indigent Policy. The researcher observed that respondents do not all have the same measures in place to ensure the successful implementation of the Indigent Policy at the City of Cape Town.

\section{Interpretation}

It was noted that the participants highlighted specific measures linked to each line function. As an example, water management devices are installed on the premises of citizens deemed indigent in an effort to reduce debt for the City of Cape Town whilst offering the indigent the opportunity to manage its' own water consumption. With the installation of this device, the indigent may save money. It was further noted that through effective records management, information regarding successful indigent households are fed into information systems. These systems are used by the City of Cape Town for the effective monitoring and evaluation of indigents through the property valuation method versus the joint household income method.

Ehlers and Lazenby (2010, p. 137) argue that ongoing observation through monitoring is essential for detecting changes in trends of programmes. It is, therefore, evident that the City of Cape Town has mechanisms in place for the monitoring of the Indigent Policy.

\section{Question 8: What staff training and development programs are in place at the City of Cape Town ensuring successful implementation of the Indigent Policy?}

\section{Response}

Respondents were all able to successfully identify training mechanisms currently in place at the City of Cape Town which deals with the Indigent Policy.

\section{Interpretation}

The researcher has established that the City of Cape Town constantly offers various forms of training and development to its staff to ensure the successful implementation of the Indigent Policy. It was further established that interventions exist dealing with staff that are not able to adequately answer pertinent questions relating to the Indigent Policy and also staff that do not follow proper protocol.

In the event that employees show a form of weakness while performing their duty, the employer should introduce a training program, which will allow the employee to acquire the required skills needed (Chron, 2017).

The researcher found that the City of Cape Town indeed has various platforms that may be utilized in the event that a specific staff member fails to meet the minimum requirement dealing with the Indigent Policy. It was further established that the employer will not hesitate to immediately address any concerns in this regard.

Question 9: How many indigents were approved during the financial year ending 30 June 2016?

\section{Response}

Four of the five respondents referred the researcher to the Director: Revenue to provide the accurate figure as of June 30, 2016. The reason for this referral was largely depended on the fact that the Director: Revenue was directly responsible for the monitoring of the indigent register. It was determined from the indigent register that the total amount of indigents as of June 30, 2016 equated 
to 2004. Furthermore, the number of beneficiaries through the valuation process amounted to 146,000 .

\section{Interpretation}

The reader should be reminded that the indigent register only caters for the citizens who has a combined household income of less than R3,500 per month. Only those who have applied will appear on the indigent register. The citizens who received benefits through the valuation process do not appear on the indigent register.

\section{Question 10: Which measures are in place to ensure that the City of Cape Town's implementation of its Indigent Policy is financially sustainable?}

\section{Response}

The financial sustainability of the Indigent Policy remains a complex situation. It requires constant effective and efficient trend analysis and long-term budgetary processes. Budgets are compiled in conjunction with line departments ensuring balanced budgets for a three year period. These long-term budgetary processes may include business plans, investment programs, as well as transversal programs.

\section{Interpretation}

The researcher is of the opinion that all of the respondents are confident that the Indigent Policy is sustainable. This is evident based on the fact that sufficient budget allocations have been made. However, should it become too expensive for the City of Cape Town to maintain the Indigent Policy, it could result in the budget of some other services such as libraries being reprioritized.

A point of concern was raised by one of the respondents pertaining to the decline in sales of electricity due to the use of alternate energy sources such as gas and solar heating. The decline of sales will result in a reduction of much needed income for the City of Cape Town.

The fundamentals of public sector financial sustainability are to be able to pay the creditors when accounts are due; the ability to endure disasters; to be able to manage debt; and to be able to maintain the confidence of the communities ensuring that the money due to the public sector is paid (Controller and Auditor-General, 2013).

The researcher has established that the City of Cape Town is in a fortunate position to collect to generate its own funds through tariffs and rates. The debt collection ratio of $95 \%$ is a positive reflection of the willingness and ability of its citizens to pay, as well as the City of Cape Town to collect. Furthermore, the City of Cape Town has received unqualified audit reports reflecting good financial management and processes.

\section{Question 11: What are the contingency plans of the City of Cape Town in the event that the number of indigents increases substantially in the short, medium and longer terms?}

\section{Response}

All participants indicated that the City of Cape Town does indeed have contingency plans in place to cater for an influx of indigent applications and that there are various intervention strategies in place.

On the short-term basis, interventions include the annual budget process; the monitoring of the register on a regular basis in order to intervene if needed; testing and analyzing of systems; good financial planning; and refining budgets and review affordability.

On the medium-to long-term basis, the City of Cape Town must maintain collecting its own funds through services rendered; receive its fair share of equitable funding from national and provincial governments; introduce interventions to limit the impact of sustainability thought debt collection, installation of prepaid meters and the eradication of illegal connections; good financial planning and modelling; and effective and efficient debt control and collection.

\section{Interpretation}

The researcher determined that the City of Cape Town does indeed have contingency plans in place to absorb the influx of indigents on both short-, as well as medium-to long-terms basis. 
It was, however, mentioned that the possibility exist that the number of people currently making use of the benefits as offered in the Indigent Policy are low. The City of Cape Town, therefore, encourages citizens who deem themselves as indigents to apply, as all the respondents have said that they want to help the people who need help with access to the essential services.

SuccessStory.com (2017) explains the importance of having a contingency plan in an organization as improving public relations; reducing the level of uncertainty; ensuring business continuity; increasing credibility and preventing panic.

It is evident that the City of Cape Town has contingency plans in place to deal with the possibility of a substantial increase in indigent applications on both the short- and medium-to long-term basis.

\section{RECOMMENDATIONS}

In an attempt to determine the level of awareness regarding the benefits of the Indigent Policy, it is recommended that the Director: Department of Area-based Service Delivery at the City of Cape Town conduct a door to door survey to assess the level of awareness of the Indigent Policy by citizens. Initiatives such as media releases may not have reached the ears of those citizens living in remote areas and, therefore, after effectively conducting the survey, the City of Cape Town could possibly be in a better position to introduce alternative communication plans such as postings on social media and door to door distribution of information brochures.

The researcher recommends that the Director: Budgets at the City of Cape Town introduces budget relocation mechanisms in the event that allocated indigent funds were not all spent for a particular financial year. Such mechanisms could include introducing an economic development initiative within the indigent areas. An example of this initiative could be conducting an entrepreneurial workshop coordinated by the Director: Department of Area-based Service Delivery in an effort to empower indigents.

The City of Cape Town's Revenue Department in collaboration with the relevant stakeholders such as sub-councils, ward forums and community forums should embark on extensive investigative campaigns in communities ensuring that each household that receives indigent benefits truly qualify. It could be that a citizen that is living in an informal settlement is earning R50,000 per month, but due to the value of the property, the person receives indigent benefits. The Director: Revenue at the City of Cape Town could possibly link the benefits of the Indigent Policy to the applicant's identity number and tax number for validation purposes.

It is recommended that the Director: Revenue in conjunction with the line departments at the City of Cape Town develops a beneficiary system for qualified indigents to allow them to additional receive benefits from other City of Cape Town facilities such as libraries, swimming pools and the MyCiTi bus services.

The researcher recommends that the Director: Department of Energy: Sustainable Energy Markets at the City of Cape Town researches the effects of alternative energy sources on the delivery of electricity by the City of Cape Town in years to come. This recommendation is based on concerns raised by research participants during the data collection of the study.

\section{CONCLUSION}

The responses of the questions that were posed to the participants during the in-depth interviews were compared with theory. The results that were analysed and that were presented per question, abled the researcher to make informed decisions.

The researcher is of the opinion that the City of Cape Town is in a position to offer assistance to indigents as described in their Indigent Policy. As a core recommendation, it is suggested that the City of Cape Town develops a beneficiary system for qualified indigents to allow them to receive additional benefits from other City of Cape Town facilities such as libraries, swimming pools and the MyCiTi bus services. 


\section{REFERENCES}

1. Areyeetey, E., Devarajan, S., Kanbur, R., \& Kasekende, L. (2012). The Oxford Companion to the economics of Africa. United Kingdom: Oxford University Press.

2. Bhorat, H., Oosthuizen, M., \& van der Westhuizen, C. (2012). Estimating a poverty line: An application to free basic municipal services in South Africa. Development Southern Africa, 29(1), 77-96. https://doi.org/10.10 80/0376835X.2012.645643

3. Black, P., Calitz, E., \& Steenekamp, T. (2008). Public Economics. Cape Town: Oxford University Press Southern Africa (Pty) Ltd.

4. Black, P., Calitz, E., \& Steenekamp, T. (2015). Public Economics. Cape Town: Oxford University Press Southern Africa (Pty) Ltd.

5. Brink, H.I., van Rensburg, G., van der Walt, C. (2012). Fundamentals of Research Methodology for Health Care Professionals (3rd ed.). Lansdowne: Juta \& Co. Ltd.

6. BusinessDictionary (2017). Data analysis.

7. Chron (2017). Importance of Training and Development in the Workplace.

8. City of Cape Town (2003). Indigent Policy: A Pro-Poor Income Strategy and Implementation Plan for the City of Cape Town. Pretoria: Government Printer.

9. City of Cape Town (2017). Apply for indigent rates relief.
10. Controller and Auditor-General (2013). Public sector financial sustainability.

11. Du Toit, D., Knipe, A., Van Niekerk, D., Van der Walt, G., \& Doyle, M. (2002). Service excellence in governance. Sandown: Heinemann Publishers (Pty) Ltd.

12. Ehlers, T., \& Lazenby, K. (2010). Strategic Management. Pretoria: Van Schaik Publishers.

13. Fink, A. (2014). Conducting Research Literature Reviews. California: SAGE Publications Inc.

14. Hennink, M., Hutter, I., \& Bailey, A. (2011). Qualitative Research Methods. London: SAGE Publications Inc.

15. Kumar, R. (2007). Research methodology: A step-by-step guide for beginners (2nd ed.). London: California. Retrieved from http:// www.sociology.kpi.ua/wp-content/ uploads/2014/06/Ranjit_KumarResearch_Methodology_A_Stepby-Step_G.pdf

16. Leedy, P. D., \& Ormrod, J. E. (2014). Practical Research. Essex: Pearson Education Ltd.

17. Morse, J. M., \& Richards, L. (2002). Readme First for a User's Guide to Qualitative Methods. London: SAGE Publications Inc.

18. Salmons, J. (2015). Qualitative Online Interviews. California: SAGE Publications Inc. Retrieved from https://onlinelibrary.wiley. com/doi/abs/10.1111/bjet.12225_6
19. Science Direct (2013). The Importance of Awareness and Education in Prevention and Control of RHD.

20. South Africa (1996). The Constitution of the Republic of South Africa Act 108 of 1996. Pretoria: Government Printer.

21. South Africa (2006). The Department of Provincial and Local Government. Municipal Indigent Policies. Pretoria: Government Printer.

22. South Africa (2013). The Presidency Department of Performance Monitoring and Evaluation. The Role of Monitoring and Evaluation in the Public Service. Pretoria: Government Printer.

23. Study.com (2017). What is Data Analyses? - Definition \& Overview.

24. SuccessStory.com (2017). 5 Benefits of Contingency Planning.

25. The South African Labor Guide (2017). Disclosure of information at interviews. Retrieved from https://www.labourguide.co.za/ pregnancy-and-the-employer/43general/general/265-disclosure-ofinformation-at-interviews

26. Thornton, P. (2015). Economics Demystified. Harlow: Pearson Education Limited.

27. Visser, C. B., \& Erasmus, P. W. (2002). The Management of Public Finance. Cape Town: Oxford University Press Southern Africa. 